\title{
The influence of war and terrorism on post- traumatic distress among Israeli children
}

\author{
Danny Brom PhD, ${ }^{1,2}$ Ruth Pat-Horenczyk PhD ${ }^{1,2}$ and Naomi L. Baum PhD ${ }^{1}$
}

${ }^{1}$ Israel Center for the Treatment of Psychotrauma; ${ }^{2}$ Hebrew University of Jerusalem, email dbrom@netvision.net.il

\begin{abstract}
The Middle East has been in conflict for many decades and wars have become the 'normative reality' of children residing in the area. Questions have been raised about children's vulnerability to the stresses that come with living in a war area. Are children more resilient because they are more flexible in their ways of coping? Or are children more vulnerable because their psychological development is influenced by the environment?

The impact of war and terrorism on children has been the focus of a growing number of studies in Israel (Solomon \& Lavi, 2005; Pat-Horenczyk et al, 2007). Related studies have investigated the effectiveness of school-based interventions designed to build resilience in the face of such trauma (Berger et al, 2007). In this brief report we focus on the impact of political violence in Israel on children, with a special emphasis on these children's post-traumatic distress. Although there is a parallel literature on Palestinian children, our focus is on the Israeli side. And, although we have extensively studied the effectiveness of protective factors that may help to shield certain children, reporting on that line of research is outside the scope of this paper.
\end{abstract}

\section{Early childhood}

The prevailing opinion is that:

$O$ even infants appear to have the ability to perceive and remember traumatic events and, consequently, develop symptoms of post-traumatic distress that are similar to those exhibited by older children and adults

$O$ the developmental skills of infants affect the phenomenology of their post-traumatic distress (Scheeringa et al, 2003).

Reactions akin to those exhibited by persons diagnosed with post-traumatic stress disorder (PTSD) have been reported among infants and pre-school children following traumatic events such as a car accident, witnessing a parent being murdered, experiencing physical or sexual abuse and being exposed to terrorist attacks or natural disasters.

Laor and colleagues conducted several studies with 3- to 5-year-old Israeli children and their mothers during three different time periods: 6 months, 30 months and 5 years after the Gulf War (see Laor et al, 2001). The results showed a clear relationship between the mothers' post-traumatic symptoms and the intensity of post-traumatic distress in their children, regardless of the amount of time elapsed after the war. On the other hand, by 30 months and 5 years after the war the post-traumatic symptoms had significantly improved, irrespective of age or gender.
Wang et al (2006) have reported that, based on maternal reports of their children's behaviour, young children's exposure to terrorism significantly increased their risk of post-traumatic distress. Another study (Pat-Horenczyk et al, 2011a) examined 255 toddlers and their mothers at risk of missile attacks. The assessment included interviews measuring maternal post-traumatic and depressive symptoms as well as evaluations of their children's behavioural, developmental and post-traumatic symptoms. There was a high prevalence of PTSD in both the young children (33\%) and their mothers (28\%). The most prevalent behavioural symptoms among the young children were low tolerance of frustration (52\%), demanding immediate attention (51\%) and sleep disorder (44\%).

In an as yet unpublished study, Pat-Horenczyk et al compared the level of post-traumatic distress in young children growing up in Sderot, an area exposed to continual missile attacks for over 7 years, with the distress of children in two Israeli cities exposed to fire during the 2006 Lebanon War (further details available on request). The children exposed to the ongoing but often harmless missile attacks manifested much higher post-traumatic distress (37\%) than the children exposed to war (approximately 12\%). Regardless of the site, there also was a strong association between maternal posttraumatic symptoms and children's distress.

\section{Mid-childhood}

Because of differences in developmental level, one might expect that the reactions of older children and adolescents to war and terrorism would be different from those of young children. Solomon \& Lavi (2005) conducted a study in middle schools and found that approximately $12 \%$ of Israeli children living in the Jerusalem area reported moderate to very severe levels of post-traumatic symptoms during the Second Intifada, when bus bombings and suicide bombers were an everyday reality. The percentage was significantly higher (27.6\%) among Israeli youths living in settlements within the occupied territories, where exposure to terrorism was even greater.

\section{Adolescence}

The prevalence of PTSD in adolescents exposed to terrorism was investigated by Pat-Horenczyk et al (2007), who found that, during the Second Intifada, 5-10\% of Israeli adolescents reported severe post-traumatic symptoms and an additional 8-10\% reported partial PTSD. 
In a large comparative study of Palestinian and Israeli youths, Pat-Horenczyk et al (2009) reported that greater exposure to conflict-related violence was associated with more post-traumatic distress and more somatic complaints, with girls reporting more distress than boys. A total of $6.8 \%$ of the Israeli students and $37.2 \%$ of the Palestinian students met criteria for PTSD.

A study carried out in Israel after the Second Lebanon War (Brom et al, 2007) based on more than 3985 youths (1761 Jewish and 2224 Arab) found that $7.2 \%$ of the Jewish students and $15.2 \%$ of the Arab students exhibited symptoms of PTSD.

Taken together, these studies indicate that both Palestinian and Israeli youths have been affected by the violence that has raged in the Middle East for many years, but particularly since the beginning of the Second Intifada.

\section{School-based interventions}

Israel, like other areas where there is ongoing conflict, has tried to deal with the relatively large groups of children who show signs of post-traumatic distress. Models of intervention have been developed that integrate community outreach, prevention and clinical approaches. Most of these models focus on educational settings and train teachers to become agents of change (Baum et al, 2009). Teachers are well placed to teach children resilience skills and to create an atmosphere of trust in the classroom. Focusing on educational environments as centres of rehabilitative activity allows students to return to a sense of normalcy while surrounded by peers and educators who can offer support. School-based interventions have an additional advantage, in that they can be delivered on a city-wide or regional scale, creating the greatest impact on the community at large. One example is the Building Resilience Intervention (BRI) model (Baum et al, 2009). It focuses on helping teachers with their own coping strategies; they can then bring into the classroom the resilience skills that they have learnt, to the benefit of their students.

Programmes have been delivered via the Israeli educational system from early childhood through to adolescence. The goals of these interventions include:

O empowerment of institutions that deal with children to become trauma-informed agents of change, strengthening resilience and children's mental health

O strengthening the resilience of teachers, parents and children

monitoring the mental health responses of children

O delivering non-stigmatising and easily accessible treatment

for children who manifest severe responses to trauma.

Such intervention programmes have been shown to be effective. In one study, teachers received 4 hours of intensive training and then administered eight classroom intervention sessions to their students to teach them post-trauma coping skills. Students' PTSD symptoms improved and no new symptoms developed (Berger et al, 2007).

\section{Conclusions}

The Israeli experience has shown that political violence affects the well-being and mental health of children. Younger children seem to be more vulnerable than older children. The symptoms of distress change along the developmental axis. In the aftermath of trauma and disaster, schools can be a major force in protecting the well-being of children. Teachers can be trained in resilience techniques aimed at increasing awareness and developing coping skills both for themselves and for their students. A promising approach is a city-wide implementation of the school-based intervention method, with the involvement of teachers, parents and community leaders (Pat-Horenczyk et al, 2011b). Particular effort should be made to adapt the model for vulnerable populations, such as minorities, immigrants and other special-needs groups. The comprehensive model for post-trauma intervention developed in Israel is applicable to many other contexts in which entire communities are affected. It should include immediate intervention, followed by a screening process designed to assess post-traumatic distress, provision of targeted interventions for teachers, parents and students, and longer-term treatment services for those with persisting needs. Clearly, the impact of trauma on children goes beyond psychopathology. Further research is needed to elucidate the complex influence of trauma on the development, behaviour and attitudes of children growing up in a war zone or in any other type of traumatised community.

\section{References}

Baum, N., Reidler, E., Rotter, B., et al (2009) Building resilience in schools in the wake of Hurricane Katrina. Journal of Child and Adolescent Trauma, 2, 62-70.

Berger, R., Pat-Horenczyk, R. \& Gelkopf, M. (2007) School-based intervention for prevention and treatment of elementary students' terror-related distress in Israel: a quasi-randomized controlled trial. Journal of Traumatic Stress, 20, 541-551.

Brom, D., Pat-Horenczyk, R., Baum, N., et al (2007) Children in the Wake of the Second Lebanese War: Findings of the City-Wide School Based Screening Process in Nahariya. Report submitted to the Municipality of Nahariya, Northern New Jersey Federation, Israel Trauma Coalition and the United Jewish Communities.

Laor, N., Wolmer, L. \& Cohen, D. J. (2001) Mothers' functioning and children's symptoms 5 years after a SCUD missile attack. American Journal of Psychiatry, 158, 1020-1026.

Pat-Horenczyk, R., Dopplet, O., Miron, T., et al (2007) Risk taking behaviors among Israeli adolescents exposed to recurrent terrorism. American Journal of Psychiatry, 164, 66-72.

Pat-Horenczyk, R., Qasrawi, R., Lesack, R., et al (2009) Posttraumatic symptoms, functional impairment and coping among adolescents on both sides of the Israeli-Palestinian conflict: a cross-cultural approach. Applied Psychology: An International Review, 58, 688-708.

Pat-Horenczyk, R., Kagan Rubenstein, A., Peled, O., et al (2011a) Growing up under fire: building resilience in toddlers and parents exposed to ongoing missile attacks. Journal of Child and Adolescent Trauma (in press).

Pat-Horenczyk, R., Brom, D., Baum, N., et al (2011b) A city-wide school-based model for addressing the needs of children exposed to terrorism and war. In Post-traumatic Syndromes in Children and Adolescents (ed. V. Ardino), pp. 243-254. Wiley/Blackwell.

Scheeringa, M. S., Zeanah, C. H., Myers, L., et al (2003) New findings on alternative criteria for PTSD in preschool children. Journal of the American Academy of Child and Adolecent Psychiatry, 42, 561-570.

Solomon, Z. \& Lavi, T. (2005) Israeli youth in the Second Intifada: PTSD and future orientation. Journal of the American Academy of Child and Adolescent Psychiatry, 44, 1167-1175.

Wang, Y., Nomura, Y., Pat-Horenczyk, R., et al (2006) Association of direct exposure to terrorism, media exposure to terrorism, and other trauma with emotional and behavioral problems in preschool children. Annals of the New York Academy of Sciences, 1094, 363368. 